\title{
Effect of adiposity on vitamin D status and the 25-hydroxycholecalciferol response to supplementation in healthy young and older Irish adults
}

\author{
L. Kirsty Forsythe ${ }^{1}$, M. Barbara E. Livingstone ${ }^{1}$, Maria S. Barnes ${ }^{1}$, Geraldine Horigan ${ }^{1}$, \\ Emeir M. McSorley ${ }^{1}$, Maxine P. Bonham ${ }^{2}$, Pamela J. Magee ${ }^{1}$, Tom R. Hill ${ }^{3}$, Alice J. Lucey ${ }^{3}$, \\ Kevin D. Cashman ${ }^{3}$, Mairead Kiely ${ }^{3}$, J. J. Strain ${ }^{1}$ and Julie M. W. Wallace ${ }^{1_{*}}$ \\ ${ }^{1}$ Northern Ireland Centre for Food and Health, University of Ulster, Coleraine BT52 1SA, UK \\ ${ }^{2}$ Department of Nutrition and Dietetics, Monash University, Clayton, Victoria, Australia \\ ${ }^{3}$ Department of Food and Nutritional Sciences, University College Cork, Cork, Republic of Ireland
}

(Received 18 August 2010 - Revised 7 April 2011 - Accepted 14 April 2011 - First published online 28 June 2011)

\section{Abstract}

There is increasing epidemiological evidence linking sub-optimal vitamin D status with overweight and obesity. Although increasing BMI and adiposity have also been negatively associated with the change in vitamin D status following supplementation, results have been equivocal. The aim of this randomised, placebo-controlled study was to investigate the associations between anthropometric measures of adiposity and the wintertime serum 25-hydroxycholecalciferol $(25(\mathrm{OH}) \mathrm{D})$ response to $15 \mu \mathrm{g}$ cholecalciferol per $\mathrm{d}$ in healthy young and older Irish adults. A total of 110 young adults (20-40 years) and 102 older adults ( $\geq 64$ years) completed the 22-week intervention with $>85 \%$ compliance. The change in $25(\mathrm{OH}) \mathrm{D}$ from baseline was calculated. Anthropometric measures of adiposity taken at baseline included height, weight and waist circumference (WC), along with skinfold thickness measurements to estimate fat mass (FM). FM was subsequently expressed as FM (kg), FM (\%), FM index (FMI (FM $\mathrm{kg} /$ height $\mathrm{m}^{2}$ )) and as a percentage ratio to fat-free mass (FFM). In older adults, vitamin D status was inversely associated with BMI $\left(\mathrm{kg} / \mathrm{m}^{2}\right)$, WC $(\mathrm{cm}), \mathrm{FM}\left(\mathrm{kg}\right.$ and \%), FMI $\left(\mathrm{kg} / \mathrm{m}^{2}\right)$ and FM:FFM $(\%)$ at baseline $(r-0.33,-0.36,-0.33,-0.30,-0.33$ and -0.27 , respectively, all $P$ values $<0.01)$. BMI in older adults was also negatively associated with the change in $25(\mathrm{OH}) \mathrm{D}$ following supplementation $(\beta-1 \cdot 27$, CI $-2 \cdot 37,-0 \cdot 16, P=0 \cdot 026)$; however, no such associations were apparent in younger adults. Results suggest that adiposity may need to be taken into account when determining an adequate wintertime dietary vitamin $\mathrm{D}$ intake for healthy older adults residing at higher latitudes.

Key words: Vitamin D status: 25-Hydroxycholecalciferol: Adiposity: BMI: Healthy adults

New functional roles of vitamin D beyond its traditional role in $\mathrm{Ca}$ homoeostasis and bone metabolism ${ }^{(1)}$ have emerged in recent years linking the fat-soluble vitamin to various non-communicable diseases. Vitamin D deficiency and suboptimal status are increasingly associated with unfavourable metabolic phenotypes including insulin resistance, type 2 diabetes, CVD and certain cancers ${ }^{(2)}$; conditions also commonly linked with overweight and obesity. Relationships between vitamin D status and obesity were first noted in the $1970 \mathrm{~s}^{(3)}$, with most subsequent studies focusing on the morbidly obese $^{(4-6)}$. However, a substantial body of evidence now indicates a more graded relationship between vitamin $\mathrm{D}$ status and $\mathrm{BMI}^{(7-9)}$, or specifically, adiposity ${ }^{(10-12)}$.

A number of hypotheses have been proposed to explain the potential mechanisms whereby alterations in the vitamin D endocrine system occur in the obese state ${ }^{(13)}$. Plausible explanations are that heavier individuals may partake in less outdoor activity owing to limited mobility and may also cover-up, wearing more clothing than leaner individuals, leading to a decreased sun exposure and therefore limiting endogenous production of vitamin D in the $\operatorname{skin}^{(4)}$. Negative feedback mechanisms from increased concentrations of 1,25-dihydroxyvitamin $\mathrm{D}_{3}$ have also been suggested, although evidence for such mechanisms is equivocal ${ }^{(5,14-16)}$. A final hypothesis is that vitamin D (as a fat-soluble vitamin) may get sequestered or 'hidden-away' in the adipose tissue, leading to lower bioavailability in the obese state ${ }^{(17,18)}$. BMI and adiposity have not only been inversely associated with vitamin D status in cross-sectional studies as mentioned previously, they have also been negatively correlated with the change in vitamin D status following supplementation, suggesting that body size and/or adiposity should be taken into account

Abbreviations: 25(OH)D, 25-hydroxycholecalciferol; FM, fat mass; FFMI, fat-free mass index; FMI, fat mass index; FFM, fat-free mass; PTH, parathyroid hormone; WAL, waist action level; WC, waist circumference.

*Corresponding author: J. M. W. Wallace, fax +44 2870123023, email j.wallace@ulster.ac.uk 
when determining the vitamin $\mathrm{D}$ intake required for optimal status $^{(19-21)}$. On the other hand, some studies have found no such association ${ }^{(22,23)}$.

Given the seasonal variation in endogenous vitamin D synthesis, especially for those residing at higher latitudes, supplementation is often recommended during the winter months only. Therefore, the aim of the present study was to investigate (1) cross-sectional associations between anthropometric measures of body size, adiposity and 25-hydroxycholecalciferol $(25(\mathrm{OH}) \mathrm{D})$, and $(2)$ the wintertime serum $25(\mathrm{OH}) \mathrm{D}$ response to supplemental cholecalciferol, in healthy young and older Irish adults participating in a randomised placebocontrolled trial.

\section{Materials and methods}

\section{Subjects}

Apparently healthy adults were equally recruited within two centres; Coleraine, Northern Ireland (latitude $55^{\circ} \mathrm{N}$ ) and Cork, Republic of Ireland (latitude $51^{\circ} \mathrm{N}$ ). The primary aim of this study was to establish the distribution of dietary requirements for the maintenance of nutritional adequacy of vitamin D during late winter by performing a randomised controlled intervention study using supplemental intakes of cholecalciferol. Inclusion criteria were consenting adults, aged $20-40$ and $\geq 64$ years recruited before the winter months in 2006 and 2007, respectively. Recruitment aimed to have similar numbers of men and women within each study population (i.e. 20 - to 40 - and $\geq 64$-year-olds). Exclusion criteria were: the use of vitamin D-containing supplements 12 weeks before the study, a planned winter vacation, use of tanning facilities, any severe medical condition or the use of medications known to interfere with vitamin D metabolism. The study was approved by the research ethics committee of the University of Ulster, Coleraine, and the clinical research ethics committee of the Cork Teaching Hospitals, University College Cork. All subjects gave written informed consent according to the guidelines laid down in the Declaration of Helsinki.

\section{Study design}

All subjects completed a validated sun exposure questionnaire (B Cullen and M Kully, unpublished results) that provided categorical information on various factors known to influence sun exposure, such as occupation, time spent outdoors, choice of clothing when outdoors and sunscreen use. Within each study population, subjects were stratified by centre, age and sex, and randomised to one of four treatment groups: 5, 10, $15 \mu \mathrm{g}$ cholecalciferol or placebo daily, for 22 weeks over the winter months. For the purpose of the present analysis, only subjects randomised to either placebo or $15 \mu \mathrm{g}$ cholecalciferol per $\mathrm{d}$ were included ( $n$ 227). The intervention period commenced in October, when vitamin D status is expected to be at its peak after the summer months and finished in March, the nadir for vitamin D status. To monitor compliance throughout this period, subjects were requested to return supplement boxes with any missed supplements at regular intervals. The number of missed supplements was then expressed relative to the number of supplements given to each subject (\%). An overnight fasting blood sample was collected by venepuncture at baseline (October) and postintervention (March) by a trained phlebotomist. All samples were processed within $3 \mathrm{~h}$ of collection and serum was frozen at $-80^{\circ} \mathrm{C}$ until analysis. Habitual dietary vitamin D intake was estimated using a validated $\mathrm{FFQ}^{(24,25)}$ with the aid of a photographic portion size food atlas ${ }^{(26)}$.

\section{Anthropometric measurements}

Anthropometric measurements included height to the nearest $0.01 \mathrm{~m}$ (using a wall-mounted stadiometer), weight to the nearest $0.01 \mathrm{~kg}$ (Seca Limited, Hamburg, Germany) and umbilical waist circumference (WC) to the nearest $0.5 \mathrm{~cm}$. BMI $\left(\mathrm{kg} / \mathrm{m}^{2}\right)$ was calculated as weight $(\mathrm{kg})$ divided by height $\left(\mathrm{m}^{2}\right)$. Skinfold thickness measurements were also obtained from four sites (subscapular, suprailiac, biceps and triceps). Body density was calculated using the sum of four skinfolds, as described by Durnin \& Womersley ${ }^{(27)}$, and from which, fat mass (FM) relative to total body weight (FM \%) was calculated using the Siri formula $(((4.95-\text { body density }) / 4.5) \times 100)^{(28)}$. Using total body weight, we then indirectly calculated FM and fat-free mass (FFM) in absolute terms ( $\mathrm{kg}$ ), adjusted them for height $^{(29)}$ and also expressed them as a percentage ratio of each other as follows:

$$
\begin{gathered}
\text { Fat mass index }\left(\mathrm{FMI}, \mathrm{kg} / \mathrm{m}^{2}\right)=\mathrm{FM}(\mathrm{kg}) / \text { height }\left(\mathrm{m}^{2}\right) \\
\text { Fat }- \text { free mass index }\left(\mathrm{FFMI}, \mathrm{kg} / \mathrm{m}^{2}\right)=\mathrm{FFM}(\mathrm{kg}) / \text { height }\left(\mathrm{m}^{2}\right)
\end{gathered}
$$

$$
\operatorname{FM}: \operatorname{FFM}(\%)=(\mathrm{FM} / \mathrm{FFM}) \times 100
$$

\section{Laboratory analysis}

Baseline and post-intervention samples were used to measure serum $25(\mathrm{OH}) \mathrm{D}$ (as a marker of vitamin D status) and serum intact parathyroid hormone (PTH) by ELISA (OCTEIA 25-Hydroxy Vitamin D; IDS Limited, Boldon, UK and MD Biosciences, Inc., St Paul, MN, USA, respectively). The intraand inter-assay $\mathrm{CV}$ were 5.9 and $6.6 \%$ for the $25(\mathrm{OH}) \mathrm{D}$ method, and 3.4 and $3.8 \%$ for the PTH method, respectively. All laboratory analyses were carried out after the intervention period as previously described ${ }^{(30,31)}$.

\section{Statistical analyses}

All data were analysed using SPSS for Windows (version 15.0; SPSS, Inc., Chicago, IL, USA). In both age groups, the Kolmogorov-Smirnov statistic was used to determine the distribution of the data (excluding age), in which any significant result $(P<0.05)$ was indicative of a non-normal distribution. Where appropriate, data were log-transformed to achieve normal (or approaching normal) distributions. This transformation was applied to $25(\mathrm{OH}) \mathrm{D}$, PTH, vitamin D intake, height, 
FM (kg and \%), FMI, FFM, FM:FFM in the younger adults, and to PTH, vitamin D intake and weight in the older adults. Descriptive statistics (means, standard deviations or medians (25th and 75th percentiles)) were used to explore the characteristics of the study populations at baseline and significant differences were determined using independent $t$ tests. The effect of intervention on vitamin D status and PTH concentration was assessed within each study population using ANCOVA, with baseline $25(\mathrm{OH}) \mathrm{D}$ as a covariate, and within each treatment group, using paired $t$ tests.

Associations between body size, adiposity and vitamin D status at baseline were tested using Pearson's partial correlations. Subjects were classified into subgroups based on the baseline anthropometric measures: BMI $\left(\mathrm{kg} / \mathrm{m}^{2}\right)$, WC $(\mathrm{cm})$, FM $(\mathrm{kg})$ and FMI $\left(\mathrm{kg} / \mathrm{m}^{2}\right)$. Established cut-offs for BMI ${ }^{(32)}$ and waist action levels (WAL) ${ }^{(33)}$, together with sex- and centre-specific tertiles of FM and FMI, were used for subgroup analysis. The vitamin D response to supplementation was then tested within the categorical and continuous data using ANOVA with Tukey post hoc tests, and ANCOVA, respectively. The PTH response to supplementation was also tested using ANCOVA. An a priori approach was applied when investigating the effect of intervention, in that, only those subjects who completed the 22-week intervention with $>85 \%$ compliance were included in the analysis. $P$ values $<0.05$ were considered statistically significant.

\section{Results}

A total of 227 adults were included in the present analysis (20- to 40-year-olds, $n 118$; $\geq 64$-year olds, $n$ 109). At baseline, 20- to 40-year-old adults had significantly higher vitamin D status and consequently lower serum PTH concentrations (both $P$ values $<0.001$ ), despite consuming a significantly lower mean daily intake of vitamin $D$ than the $\geq 64$-year olds ( $P=0.004$; data not shown). There was no difference in baseline vitamin $\mathrm{D}$ status between men and women in the younger group (80.7 (SD 33.2) v. 75.6 (SD 32.5); $P=0.311$ ), however, older men had significantly higher vitamin D status compared to older women (61.5 (SD 23.5) v. 53.5 (SD 18.4); $P=0 \cdot 049$ ). Within both age groups, men consumed significantly more vitamin D per $\mathrm{d}$ on average than women $(5 \cdot 1$ (SD 3.6) v. 3.5 (SD 2.3); $P=0.003$, and 5.8 (SD 3.3) v. 4.6 (SD 2.7) $P=0.028$, in the 20 - to 40 - and $\geq 64$-year-olds, respectively). As expected, all anthropometric measures of adiposity, with the exception of BMI, were significantly different between men and women within each age group (all $P$ values $<0.05$; data not shown). Furthermore, baseline vitamin D status was also significantly higher in those recruited in Cork than those from Coleraine (88.3 (SD 36.5) v. 68.2 (SD 25.4); $P=0.001$, and 62.3 (SD 23.5) v. 52.3 (SD 17.6); $P=0.012$, in the 20 - to 40 - and $\geq 64$-year-olds, respectively). Owing to these differences, all further analyses were adjusted for sex and recruitment centre, and were carried out in each age group separately.

In terms of baseline characteristics, there were no significant differences in any characteristic between the treatment groups in either age group (Table 1). In the 20- to 40-year-olds, there were five and three dropouts from the placebo and $15 \mu \mathrm{g} / \mathrm{d}$ groups, respectively; all other subjects completed the 22 -week intervention with $>85 \%$ compliance. Among the $\geq 64$-year olds, two subjects in the placebo group did not complete the study and a further two and three subjects from the placebo and supplemental groups, respectively, were excluded for non-compliance. Reasons for dropouts were unrelated to the intervention. There were no significant differences in terms of baseline vitamin D status, body size or adiposity between those who completed the study ( $n 110$ and $n$ 102) and those who were excluded through dropout or non-compliance ( $n 8$ and $n 7$ ) in both the young and the older adults, respectively (data not shown). The effect of the intervention on vitamin D status and PTH concentrations is shown in Table 2. Vitamin D status at baseline was significantly associated with sun exposure in both young ${ }^{(30)}$ and older $^{(31)}$ adults, therefore, to take account for such differences, and subsequently the previous summertime endogenous production of vitamin $\mathrm{D}$, all longitudinal analysis was controlled for baseline $25(\mathrm{OH}) \mathrm{D}$. In younger adults, a non-significant decline in vitamin $\mathrm{D}$ status and a significant increase in PTH concentration were evident over the winter months in the group supplemented with $15 \mu \mathrm{g}$ cholecalciferol per $\mathrm{d}$ ( $P=0.193$ and 0.011 , respectively), whereas in the $\geq 64$-year olds, supplementation significantly increased vitamin D status with no significant change in PTH concentration $(P<0 \cdot 001$ and $0 \cdot 180$, respectively).

At baseline, 25(OH)D was not significantly correlated with any anthropometric index in younger adults (Table 3) and the change in $25(\mathrm{OH}) \mathrm{D}$ following supplementation was not significantly influenced by body size or adiposity, in either the placebo or the $15 \mu \mathrm{g}$ cholecalciferol per $\mathrm{d}$ groups (data not shown). However, in the $\geq 64$-year-old adults, baseline 25(OH)D concentration was significantly negatively correlated with BMI $\left(\mathrm{kg} / \mathrm{m}^{2}\right)$, WC $(\mathrm{cm})$, FM $(\mathrm{kg})$, FM (\%), FMI $\left(\mathrm{kg} / \mathrm{m}^{2}\right)$ and FM:FFM (\%) $(r-0.33,-0.36,-0.33,-0.30,-0.33$ and $-0 \cdot 27$, respectively; all $P$ values $<0 \cdot 01$; Table 3 ). When ANCOVA adjusted for sex, recruitment centre and baseline $25(\mathrm{OH}) \mathrm{D}$ concentration was used to test the effect of body size and adiposity on the $25(\mathrm{OH}) \mathrm{D}$ response to supplemental cholecalciferol, only BMI was significantly and negatively associated with change in $25(\mathrm{OH}) \mathrm{D}$ in the older adults (Table 4). In addition, categorical analyses showed the change in $25(\mathrm{OH}) \mathrm{D}$ was also associated with measures of body size and adiposity in the older placebo group (Fig. 1(A)-(D)). Individuals classified as obese (BMI $\geq 30 \cdot 0 \mathrm{~kg} / \mathrm{m}^{2}$ ), or in WAL 2 (WC $\geq 102 \mathrm{~cm}$ in men and $\geq 88 \mathrm{~cm}$ in women) and randomised to the placebo group had a significantly smaller decline in $25(\mathrm{OH}) \mathrm{D}$ over the winter months compared with those classified as normal weight (BMI $<25.0 \mathrm{~kg} / \mathrm{m}^{2}$ ) or below WAL 1 (WC $<94 \mathrm{~cm}$ in men and $<80 \mathrm{~cm}$ in women). Individuals in the middle and highest tertiles of FM ( $\mathrm{kg}$ ) and randomised to the placebo group tended to have a smaller decline in $25(\mathrm{OH}) \mathrm{D}$ compared with those in the lowest tertile; however, the change only reached significance between the lowest and middle tertiles. Similar trends were also apparent between the tertiles of FMI $\left(\mathrm{kg} / \mathrm{m}^{2}\right)$, but this did not reach significance. ANCOVA investigating 
Table 1. Baseline characteristics by treatment group*

(Medians, number of subjects, and 25th and 75th percentiles)

\begin{tabular}{|c|c|c|c|c|c|c|c|c|c|c|c|c|c|c|}
\hline & \multicolumn{7}{|c|}{20 - to 40 -year-olds } & \multicolumn{7}{|c|}{$\geq 64$-year-olds } \\
\hline & \multicolumn{3}{|c|}{ Placebo ( $n$ 62) } & \multicolumn{4}{|c|}{$15 \mu \mathrm{g} / \mathrm{d}(n 56)$} & \multicolumn{3}{|c|}{ Placebo ( $n 58)$} & \multicolumn{4}{|c|}{$15 \mu \mathrm{g} / \mathrm{d}(n 51)$} \\
\hline & Median & $\begin{array}{c}\text { 25th } \\
\text { percentile }\end{array}$ & $\begin{array}{c}\text { 75th } \\
\text { percentile }\end{array}$ & Median & $\begin{array}{c}\text { 25th } \\
\text { percentile }\end{array}$ & $\begin{array}{c}\text { 75th } \\
\text { percentile }\end{array}$ & $P \dagger$ & Median & $\begin{array}{c}\text { 25th } \\
\text { percentile }\end{array}$ & $\begin{array}{c}\text { 75th } \\
\text { percentile }\end{array}$ & Median & $\begin{array}{c}\text { 25th } \\
\text { percentile }\end{array}$ & $\begin{array}{c}\text { 75th } \\
\text { percentile }\end{array}$ & $P+$ \\
\hline \multicolumn{15}{|l|}{$\operatorname{Sex}(n)$} \\
\hline Male & 30 & & & 28 & & & & 24 & & & 21 & & & \\
\hline Female & 32 & & & 28 & & & & 34 & & & 30 & & & \\
\hline Age (years) & $29 \cdot 0$ & $23 \cdot 8$ & $35 \cdot 3$ & $28 \cdot 0$ & $23 \cdot 2$ & $36 \cdot 8$ & 0.944 & $68 \cdot 0$ & $66 \cdot 0$ & $72 \cdot 3$ & $71 \cdot 0$ & $67 \cdot 0$ & $75 \cdot 0$ & 0.246 \\
\hline $25(\mathrm{OH}) \mathrm{D}(\mathrm{nmol} / \mathrm{l})$ & $66 \cdot 13$ & 56.5 & $96 \cdot 3$ & $75 \cdot 88$ & 55.6 & 89.5 & 0.668 & $57 \cdot 82$ & $40 \cdot 2$ & 78.5 & 54.80 & 38.5 & $69 \cdot 6$ & 0.326 \\
\hline PTH (ng/l) & 49.69 & 32.5 & 60.5 & 38.52 & 29.1 & $50 \cdot 4$ & 0.191 & $47 \cdot 89$ & 39.5 & $67 \cdot 2$ & 53.78 & $42 \cdot 2$ & $67 \cdot 8$ & 0.378 \\
\hline Vitamin D intake $(\mu \mathrm{g} / \mathrm{d})$ & $3 \cdot 24$ & $2 \cdot 0$ & $5 \cdot 3$ & 3.53 & $2 \cdot 2$ & $5 \cdot 7$ & 0.846 & 4.72 & $2 \cdot 7$ & $6 \cdot 7$ & 4.72 & $2 \cdot 6$ & $6 \cdot 4$ & 0.832 \\
\hline Height $(m)$ & 1.71 & 1.6 & 1.8 & 1.70 & 1.6 & 1.8 & 0.254 & 1.63 & 1.6 & 1.7 & 1.64 & 1.6 & $1 \cdot 7$ & 0.750 \\
\hline Weight (kg) & $76 \cdot 10$ & $64 \cdot 1$ & $85 \cdot 6$ & $75 \cdot 80$ & 68.0 & 87.0 & 0.332 & $77 \cdot 40$ & $66 \cdot 6$ & $87 \cdot 0$ & $75 \cdot 20$ & $69 \cdot 8$ & 88.4 & 0.540 \\
\hline BMI $\left(\mathrm{kg} / \mathrm{m}^{2}\right)$ & $25 \cdot 90$ & $22 \cdot 4$ & $28 \cdot 8$ & $25 \cdot 27$ & 23.8 & 29.5 & 0.338 & $28 \cdot 46$ & $25 \cdot 1$ & $31 \cdot 7$ & $28 \cdot 86$ & $26 \cdot 1$ & $32 \cdot 7$ & 0.664 \\
\hline WC (cm) & 85.90 & $77 \cdot 3$ & $96 \cdot 1$ & $86 \cdot 50$ & $79 \cdot 1$ & $96 \cdot 7$ & 0.404 & 93.05 & $86 \cdot 0$ & $105 \cdot 2$ & 96.00 & 88.0 & $101 \cdot 0$ & 0.683 \\
\hline FM (kg) & $18 \cdot 70$ & $13 \cdot 9$ & $22 \cdot 8$ & $17 \cdot 85$ & $13 \cdot 8$ & 25.5 & 0.553 & $26 \cdot 39$ & 21.9 & 32.4 & 28.23 & 24.5 & 33.3 & 0.133 \\
\hline FM (\%) & 25.05 & $20 \cdot 0$ & $30 \cdot 1$ & $25 \cdot 10$ & $17 \cdot 7$ & $35 \cdot 1$ & 0.896 & $35 \cdot 77$ & $28 \cdot 7$ & 39.8 & $37 \cdot 77$ & $32 \cdot 8$ & $42 \cdot 3$ & 0.132 \\
\hline FMI $\left(\mathrm{kg} / \mathrm{m}^{2}\right)$ & 6.02 & $5 \cdot 0$ & $8 \cdot 3$ & $6 \cdot 14$ & 4.2 & $8 \cdot 7$ & 0.678 & $10 \cdot 03$ & 7.9 & 12.5 & $10 \cdot 96$ & 8.9 & 13.5 & $0 \cdot 162$ \\
\hline FFM (kg) & 54.32 & $45 \cdot 2$ & 68.5 & $56 \cdot 89$ & $46 \cdot 9$ & 67.5 & 0.638 & $49 \cdot 12$ & 41.6 & $56 \cdot 4$ & 47.97 & $42 \cdot 3$ & $57 \cdot 2$ & 0.659 \\
\hline FFMI $\left(\mathrm{kg} / \mathrm{m}^{2}\right)$ & $19 \cdot 24$ & $16 \cdot \overline{6}$ & 21.9 & 18.90 & $17 \cdot 2$ & 21.4 & 0.839 & $18 \cdot 06$ & $16 \cdot 2$ & $20 \cdot 6$ & $18 \cdot 19$ & $16 \cdot 8$ & $20 \cdot 2$ & 0.555 \\
\hline FM:FFM (\%) & 33.42 & $25 \cdot 0$ & 43.0 & 33.53 & $21 \cdot 6$ & $54 \cdot 1$ & 0.779 & 55.69 & $40 \cdot 3$ & $66 \cdot 2$ & $60 \cdot 68$ & 48.9 & $73 \cdot 2$ & 0.125 \\
\hline
\end{tabular}

25(OH)D, serum 25-hydroxycholecalciferol; PTH, parathyroid hormone; WC, waist circumference; FM, fat mass; FMI, fat mass index; FFM, fat-free mass; FFMI, fat-free mass index.

* Vitamin D intake estimated from a validated FFQ.

$\dagger$ No significant differences between the treatment groups within each age group, all $P>0.05$ (independent $t$ test). 
the PTH response to supplemental cholecalciferol showed no significant effect of body size or adiposity, after controlling for sex, recruitment centre and baseline PTH concentration (data not shown).

\section{Discussion}

Overall, this study observed significant negative associations between baseline 25(OH)D and all anthropometric measures of body size and adiposity in a group of healthy older adults, aged 64 years and over. Furthermore in this group, the $25(\mathrm{OH}) \mathrm{D}$ response to supplemental cholecalciferol $(15 \mu \mathrm{g} / \mathrm{d})$ over the winter months was also negatively associated with baseline BMI, whereby the mean adjusted change in $25(\mathrm{OH}) \mathrm{D}$ decreased by approximately $6.5 \mathrm{nmol} / \mathrm{l}$ with every $5 \mathrm{~kg} / \mathrm{m}^{2}$ increase in BMI at baseline. In contrast, no such relationships were apparent between body size, adiposity and baseline vitamin D status, or the vitamin D response to supplementation in younger adults (20-40 years).

A number of previous studies in older populations have also reported an inverse relationship between $\mathrm{BMI}^{(7,20,21)}$ and/or measures of body fat ${ }^{(11,34,35)}$ and vitamin D status. In the present study, a stronger relationship was observed when FMI $\left(\mathrm{kg} / \mathrm{m}^{2}\right)$ (i.e. FM adjusted for height) was used in the analysis instead of FM (\%), an index not previously reported. An inverse relationship between adiposity and the decline in $25(\mathrm{OH}) \mathrm{D}$ over the winter months was also observed in older adults in the placebo group, which concurs with previous findings in both older men ${ }^{(36)}$ and postmenopausal women ${ }^{(11,17)}$. Overall, in older adults, while baseline vitamin D status (primarily reflective of synthesis via UV-B during the summer months) was inversely associated with body size and adiposity, adiposity appeared to attenuate the natural seasonal decline in vitamin D status over the winter months, when vitamin $\mathrm{D}$ synthesis is absent. This finding may be attributed to the sequestration theory, suggested by Wortsman et al. ${ }^{(18)}$, that proposed that with increasing adiposity, more vitamin $\mathrm{D}$ is stored or trapped in adipose tissue following UV-B synthesis, leading to lower vitamin D status. Findings from the present study suggest that this sequestration in body fat may in fact act as a wintertime reservoir of vitamin $\mathrm{D}$; however, this could only be confirmed by quantifying the vitamin $\mathrm{D}$ content of adipose tissue.

The inverse association observed in the present study between BMI and the 25(OH)D response to supplementation in older adults has also been noted in previous studies ${ }^{(20,21)}$. In addition, Blum et al. ${ }^{(20)}$ reported inverse relationships between the change in $25(\mathrm{OH}) \mathrm{D}$ following supplementation and WC $(\mathrm{cm})$, total FM (kg) and central FM (kg), albeit weaker associations than those noted for BMI. Inconsistencies in study findings between Blum et al. ${ }^{(20)}$ and the present study could be explained by the different methods used to assess adiposity. Blum et al. ${ }^{(20)}$ used dual-energy X-ray absorptiometry, which may be considered a more robust measure of adiposity than skinfold thickness measurements. On the other hand, the present finding of no relationship between any measure or index of $\mathrm{FM}$ and the $25(\mathrm{OH}) \mathrm{D}$ response to 
Table 3. Partial correlation matrix at baseline in each study population

(Pearson's partial correlation coefficients)

\begin{tabular}{|c|c|c|c|c|c|c|c|}
\hline & $25(\mathrm{OH}) \mathrm{D}(\mathrm{nmol} / \mathrm{l})$ & BMI $\left(\mathrm{kg} / \mathrm{m}^{2}\right)$ & WC $(\mathrm{cm})$ & $\mathrm{FM}(\mathrm{kg})$ & FM (\%) & $\mathrm{FMI}\left(\mathrm{kg} / \mathrm{m}^{2}\right)$ & FM:FFM (\%) \\
\hline $25(\mathrm{OH}) \mathrm{D}(\mathrm{nmol} / \mathrm{l})$ & & $0.00 \dagger$ & $-0.03 \dagger$ & $-0.06 \dagger$ & $-0.13 \dagger$ & $-0.07 \dagger$ & $-0.12 \dagger$ \\
\hline BMI $\left(\mathrm{kg} / \mathrm{m}^{2}\right)$ & $-0.33^{\star} \ddagger$ & & $0.91^{*} \dagger$ & $0.88^{*} \dagger$ & $0.72^{*} \dagger$ & $0.91^{*} \dagger$ & $0.75^{\star} \dagger$ \\
\hline$W C(\mathrm{~cm})$ & $-0.36^{\star} \ddagger$ & $0 \cdot 86^{\star} \ddagger$ & & $0.88^{*} \dagger$ & $0.74^{*} \dagger$ & $0.88^{*} \dagger$ & $0.76^{*} \dagger$ \\
\hline $\mathrm{FM}(\mathrm{kg})$ & $-0.33^{*} \ddagger$ & $0 \cdot 85^{\star} \ddagger$ & $0.84^{*} \ddagger$ & & $0.93^{*} \dagger$ & $0.98^{*} \dagger$ & $0.94^{*} \dagger$ \\
\hline FM (\%) & $-0.30^{*} \ddagger$ & $0.57^{\star} \ddagger$ & $0.55^{\star} \ddagger$ & $0.82^{*} \ddagger$ & & $0.95^{\star} \dagger$ & $1.00^{*} \dagger$ \\
\hline FMI $\left(\mathrm{kg} / \mathrm{m}^{2}\right)$ & $-0.33^{\star} \ddagger$ & $0.93^{\star} \ddagger$ & $0.82^{*} \ddagger$ & $0.94^{*} \ddagger$ & $0.83^{\star} \ddagger$ & & $0.96^{*} \dagger$ \\
\hline FM:FFM (\%) & $-0.27^{\star} \ddagger$ & $0.52^{\star} \ddagger$ & $0.50^{*} \ddagger$ & $0.78^{*} \ddagger$ & $0.98^{\star} \ddagger$ & $0 \cdot 80^{\star} \ddagger$ & \\
\hline
\end{tabular}

25(OH)D, serum 25-hydroxycholecalciferol; WC, waist circumference; FM, fat mass; FMI, fat mass index; FFM, fat-free mass.

* Pearson's partial correlation coefficient $(r)$ adjusted for sex and recruitment centre $(P<0.01)$.

† 20- to 40-year-olds (n 118).

$\ddagger \geq 64$-year-olds ( $n$ 109).

supplementation in this age group is in agreement with an earlier study in institutionalised older adults that used tertiles of FM (\%) in their analysis ${ }^{(22)}$. In the older group in the present analysis, supplementation also had a significant effect on PTH concentrations, however, as no effect of body size or adiposity on the change in PTH was evident, the significant increase in vitamin D status is the most plausible explanation for the PTH response to supplemental cholecalciferol.

In the younger adults, no associations were observed between baseline vitamin D status and any anthropometric measure of body size or adiposity, which is at variance to findings previously reported for similar age groups ${ }^{(8,23,37)}$. Furthermore, no associations were observed between baseline adiposity and the $25(\mathrm{OH}) \mathrm{D}$ or PTH response to supplementation. The majority of previous cross-sectional studies investigating vitamin D and obesity, more often than not have used BMI categories or cut-offs as a proxy measure of adiposity, e.g. obese $v$. non-obese (BMI $\geq 30$ and $<30 \mathrm{~kg} / \mathrm{m}^{2}$ ), which could result in stronger associations, than when BMI is used as a continuous variable. Two previous studies in younger adults have investigated the association between body size or adiposity and the $25(\mathrm{OH}) \mathrm{D}$ response to supplementation; however, results have been equivocal ${ }^{(19,23)}$.

The findings from the present study, that anthropometric measures of body size and adiposity are associated with vitamin D status at baseline, the seasonal decline in vitamin D status over the winter months, and also the change in vitamin D status following supplementation in older, but not younger adults, could be indicative of fundamental age-related differences in vitamin $\mathrm{D}$ metabolism ${ }^{(38)}$. Previous research reported that the serum $25(\mathrm{OH}) \mathrm{D}$ response $24 \mathrm{~h}$ after an oral dose of vitamin $\mathrm{D}_{2}$ was the same in both lean and obese younger adults ${ }^{(18)}$, but no such research has been undertaken in older population groups. The present findings, however, may also be explained by other factors rather than age-associated changes in vitamin D metabolism. It is well known that adiposity increases with age and vitamin D status is reported to be lower in older adults ${ }^{(39,40)}$; the findings of the present study are in keeping with such reports. Therefore, it is possible that relationships between adiposity and vitamin D status may only be apparent when baseline adiposity is higher and vitamin D status is lower, as observed in older adults in the present analysis. Indeed, it could be hypothesised that if we had recruited a younger study population with similar baseline vitamin D status and adiposity as reported in our older population, similar associations between adiposity and vitamin D status may have been evident.

The present study has particular strengths and limitations. Although the sample size was small, the study had a randomised placebo-controlled design and was therefore ideal for investigating the impact of body size and adiposity on the $25(\mathrm{OH}) \mathrm{D}$ response to cholecalciferol supplementation. Undertaking the intervention only in wintertime also ensured that there would be no confounding of the results by endogenous synthesis of $25(\mathrm{OH}) \mathrm{D}$ and furthermore, compliance was very good with $93 \%$ of the volunteers recruited consuming

Table 4. Effect of adiposity on 25 -hydroxycholecalciferol $(25(\mathrm{OH}) \mathrm{D})$ response to supplementation in $\geq 64$-year-old adults* ( $\beta$ Coefficients and $95 \%$ confidence intervals)

\begin{tabular}{|c|c|c|c|c|c|c|}
\hline & \multicolumn{3}{|c|}{ Placebo ( $n 54)$} & \multicolumn{3}{|c|}{$15 \mu \mathrm{g} / \mathrm{d}(n 48)$} \\
\hline & $\beta$ & $95 \% \mathrm{Cl}$ & $P$ & $\beta$ & $95 \% \mathrm{Cl}$ & $P$ \\
\hline BMI $\left(\mathrm{kg} / \mathrm{m}^{2}\right)$ & 0.32 & $-0.62,1.25$ & 0.499 & -1.27 & $-2.37,-0.16$ & $0.026 \dagger$ \\
\hline$W C(\mathrm{~cm})$ & 0.43 & $-0.28,0.37$ & 0.795 & -0.41 & $-0.85,0.37$ & 0.072 \\
\hline FM (kg) & 0.05 & $-0.52,0.61$ & 0.870 & -0.36 & $-1.05,0.32$ & 0.288 \\
\hline $\mathrm{FMI}\left(\mathrm{kg} / \mathrm{m}^{2}\right)$ & $0 \cdot 17$ & $-1.38,1.73$ & 0.823 & -1.63 & $-3.51,0.26$ & 0.089 \\
\hline
\end{tabular}

WC, waist circumference; FM, fat mass; FMI, fat mass index.

${ }^{*}$ Each model included baseline $25(\mathrm{OH}) \mathrm{D}$, age, sex and recruitment centre as covariates.

$\dagger$ Significant association with the change in serum 25(OH)D from baseline (ANCOVA; $P<0.05$ ) 

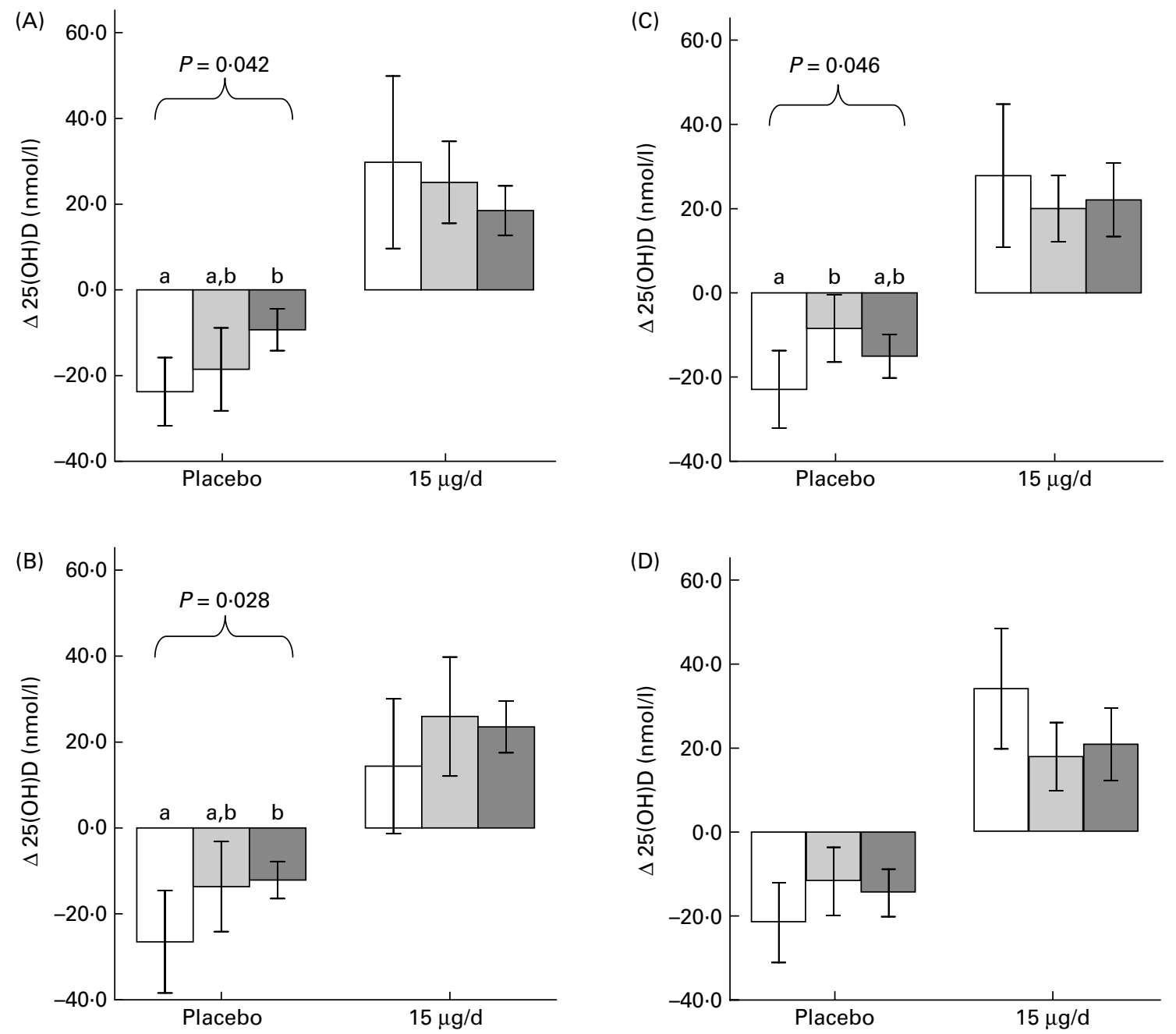

Fig. 1. Mean (SEM 2) change in serum 25-hydroxycholecalciferol (25(OH)D) (nmol/l) in $\geq 64$-year-old adults $(n$ 102) by $(A)$ BMI categories ( $\square$, BMI $<25 \cdot 0 ; \square$, BMI 25.0-29.9; $\square, \mathrm{BMI} \geq 30.0$ ); (B) sex-specific waist action levels (WAL 1: male (M), $\geq 94 \mathrm{~cm}$ and female (F), $\geq 80 \mathrm{~cm} ; W A L 2: M, \geq 102 \mathrm{~cm}$ and $\mathrm{F}, \geq 88 \mathrm{~cm}$ ).

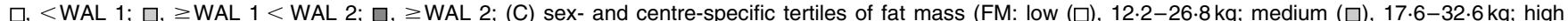

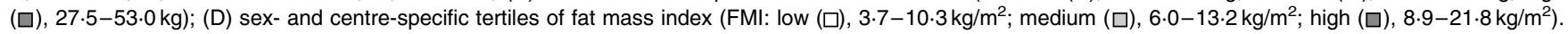
Significant differences between groups determined by within-treatment group ANOVA. Values are means, with their standard errors represented by vertical bars. ${ }^{\mathrm{a}, \mathrm{b}}$ Mean values with unlike letters were significantly different within the groups by Tukey post hoc tests $(P<0.05)$.

$>85 \%$ of the supplements provided. In the present study skinfold thickness measurements were used to estimate FM. Although skinfold-assessed adiposity has been shown to agree well with other direct measures of adiposity ${ }^{(27)}$, such assessments are prone to inter- and intra-observer bias of uncertain magnitude and direction. To minimise such measurement error, all investigators were trained in these measures at one centre to standardise the methodology. A particular strength of the current analysis, we believe, was the inclusion of the measure of adiposity, FMI, i.e. FM adjusted for height $\left(\mathrm{kg} / \mathrm{m}^{2}\right)$. Within the literature, the most common method of reporting $\mathrm{FM}$ is as a percentage relative to total body weight but this method has a number of limitations ${ }^{(29,41,42)}$. Owing to the fact that FM (the numerator) is also a component of total body weight (the denominator), differences in adiposity between lean and obese individuals can be underestimated, which can be avoided by adjusting FM for height (FMI) rather than total body weight. It is recommended that future studies investigating the influence of adiposity on vitamin D status should use more direct measures of adiposity, appropriately adjusted for body size.

In conclusion, in the present study vitamin D status was inversely associated with anthropometric measures of adiposity at baseline, and BMI was also inversely associated with the change in vitamin D status following supplementation in older ( $\geq 64$ years), but not younger Irish adults (20-40 years). If wintertime supplementation is recommended to those residing at higher latitudes, these results suggest that body weight status, as assessed by BMI, may need to be taken into account when determining an adequate dose for healthy older adults.

\section{Acknowledgements}

This research was funded by the Department of Employment and Learning, and the UK Food Standards Agency. The 
authors' responsibilities were as follows: J. J. S., J. M. W. W., E. M. McS., M. P. B., P. J. M., K. D. C. and M. K. designed the research. L. K. F., M. S. B., G. H., T. R. H. and A. J. L. conducted the research. L. K. F. and M. S. B, analysed the data. L. K. F., M. B. E. L. and J. M. W. W. interpreted the results and prepared the manuscript. All the authors read and approved the final manuscript. The authors have no conflict of interest. We thank statisticians at the Northern Ireland Clinical Research Support Centre, Belfast for statistical advice and Miss Carol Wilson for her comments on drafts of this manuscript. We are also very grateful to volunteers from both centres who participated in this research.

\section{References}

1. Suda T, Ueno Y, Fujii K, et al. (2003) Vitamin D and bone. $J$ Cell Biochem 88, 259-266.

2. Holick MF (2007) Vitamin D deficiency. $N$ Engl J Med 357, 266-281.

3. Lumb GA, Mawer EB \& Stanbury SW (1971) The apparent vitamin $\mathrm{D}$ resistance of chronic renal failure: a study of the physiology of vitamin D in man. Am J Med 50, 421-441.

4. Compston JE, Vedi S, Ledger JE, et al. (1981) Vitamin D status and bone histomorphometry in gross obesity. Am J Clin Nutr 34, 2359-2363.

5. Bell NH, Epstein S, Greene A, et al. (1985) Evidence for alteration of the vitamin D-endocrine system in obese subjects. J Clin Invest 76, 370-373.

6. Liel Y, Ulmer E, Shary J, et al. (1988) Low circulating vitamin $\mathrm{D}$ in obesity. Calcif Tissue Int 43, 199-201.

7. Jacques PF, Felson DT, Tucker KL, et al. (1997) Plasma 25-hydroxyvitamin D and its determinants in an elderly population sample. Am J Clin Nutr 66, 929-936.

8. Nesby-O'Dell S, Scanlon KS, Cogswell ME, et al. (2002) Hypovitaminosis D prevalence and determinants among African American and white women of reproductive age: third National Health and Nutrition Examination Survey, 1988-1994. Am J Clin Nutr 76, 187-192.

9. Hypponen E \& Power C (2006) Vitamin D status and glucose homeostasis in the 1958 British birth cohort: the role of obesity. Diabetes Care 29, 2244-2246.

10. Arunabh S, Pollack S, Yeh J, et al. (2003) Body fat content and 25-hydroxyvitamin D levels in healthy women. J Clin Endocrinol Metab 88, 157-161.

11. Bolland MJ, Grey AB, Ames RW, et al. (2007) The effects of seasonal variation of 25-hydroxyvitamin D and fat mass on a diagnosis of vitamin D sufficiency. Am J Clin Nutr 86, 959-964.

12. Ernst B, Thurnheer M, Schmid SM, et al. (2009) Seasonal variation in the deficiency of 25-hydroxyvitamin $\mathrm{D}(3)$ in mildly to extremely obese subjects. Obes Surg 19, 180-183.

13. Looker AC (2007) Do body fat and exercise modulate vitamin D status? Nutr Rev 65, S124-S126.

14. Bell NH, Shaw S \& Turner RT (1984) Evidence that 1,25-dihydroxyvitamin D3 inhibits the hepatic production of 25-hydroxyvitamin D in man. J Clin Invest 74, 1540-1544.

15. Parikh SJ, Edelman M, Uwaifo GI, et al. (2004) The relationship between obesity and serum 1,25-dihydroxy vitamin D concentrations in healthy adults. J Clin Endocrinol Metab 89, 1196-1199.

16. Konradsen S, Ag H, Lindberg F, et al. (2008) Serum 1,25dihydroxy vitamin $\mathrm{D}$ is inversely associated with body mass index. Eur J Nutr 47, 87-91.
17. Need AG, Morris HA, Horowitz M, et al. (1993) Effects of skin thickness, age, body fat, and sunlight on serum 25-hydroxyvitamin D. Am J Clin Nutr 58, 882-885.

18. Wortsman J, Matsuoka LY, Chen TC, et al. (2000) Decreased bioavailability of vitamin D in obesity. Am J Clin Nutr $\mathbf{7 2}$, 690-693.

19. Barger-Lux MJ, Heaney RP, Dowell S, et al. (1998) Vitamin D and its major metabolites: serum levels after graded oral dosing in healthy men. Osteoporos Int 8, 222-230.

20. Blum M, Dallal GE \& Dawson-Hughes B (2008) Body size and serum 25 hydroxy vitamin D response to oral supplements in healthy older adults. J Am Coll Nutr 27, $274-279$

21. Lee P, Greenfield JR, Seibel MJ, et al. (2009) Adequacy of vitamin D replacement in severe deficiency is dependent on body mass index. Am J Med 122, 1056-1060.

22. Canto-Costa MH, Kunii I \& Hauache OM (2006) Body fat and cholecalciferol supplementation in elderly homebound individuals. Braz J Med Biol Res 39, 91-98.

23. Nelson ML, Blum JM, Hollis BW, et al. (2009) Supplements of $20 \mathrm{microg} / \mathrm{d}$ cholecalciferol optimized serum 25-hydroxyvitamin D concentrations in $80 \%$ of premenopausal women in winter. $J$ Nutr 139, 540-546.

24. Hill T, Collins A, O'Brien M, et al. (2005) Vitamin D intake and status in Irish postmenopausal women. Eur J Clin Nutr 59, 404-410.

25. Collins A (2006) Development and validation of methods for the measurement of micronutrient intakes relevant to bone health. PhD Thesis, The National University of Ireland.

26. Ministry of Agriculture, Fisheries and Food (MAFF) (1997) Food Portion Sizes. London: The Stationary Office.

27. Durnin JV \& Womersley J (1974) Body fat assessed from total body density and its estimation from skinfold thickness: measurements on 481 men and women aged from 16 to 72 years. Br J Nutr 32, 77-97.

28. Siri WE (1956) The gross composition of the body. In Advances in Biological and Medical Physics, pp. 239-280 [CA Tobias and JH Lawrence, editors]. New York: Academic Press.

29. VanItallie TB, Yang M, Heymsfield SB, et al. (1990) Heightnormalized indicies of the body's fat-free mass and fat mass: potentially useful indicators of nutritional status. Am J Clin Nutr 52, 953-959.

30. Cashman KD, Hill TR, Lucey AJ, et al. (2008) Estimation of the dietary requirement for vitamin $\mathrm{D}$ in healthy adults. Am J Clin Nutr 88, 1535-1542.

31. Cashman KD, Wallace JM, Horigan G, et al. (2009) Estimation of the dietary requirement for vitamin $\mathrm{D}$ in freeliving adults $>=64$ y of age. Am J Clin Nutr 89, 1366-1374.

32. World Health Organisation (2000) Obesity: Preventing and Managing the Global Epidemic no. 894. Geneva: WHO.

33. Han TS, van Leer EM, Seidell JC, et al. (1995) Waist circumference action levels in the identification of cardiovascular risk factors: prevalence study in a random sample. BMJ 311, 1401-1405.

34. Snijder MB, van Dam RM, Visser M, et al. (2005) Adiposity in relation to vitamin D status and parathyroid hormone levels: a population-based study in older men and women. J Clin Endocrinol Metab 90, 4119-4123.

35. Moschonis G, Tanagra S, Koutsikas K, et al. (2009) Association between serum 25-hydroxyvitamin D levels and body composition in postmenopausal women: the postmenopausal Health Study. Menopause 16, 701-707.

36. Lagunova Z, Porojnicu AC, Lindberg F, et al. (2009) The dependency of vitamin D status on body mass index, gender, age and season. Anticancer Res 29, 3713-3720. 
37. Winters SJ, Chennubhatla R, Wang C, et al. (2009) Influence of obesity on vitamin D-binding protein and 25-hydroxy vitamin D levels in African American and white women. Metab Clin Exp 58, 438-442.

38. MacLaughlin J \& Holick MF (1985) Aging decreases the capacity of human skin to produce vitamin $\mathrm{D}_{3} . J$ Clin Invest 76, 1536-1538.

39. Lester E, Skinner RK \& Wills MR (1977) Seasonal variation in serum-25-hydroxyvitamin-D in the elderly in Britain. Lancet $\mathbf{i}, 979-980$.
40. Hirani V \& Primatesta P (2005) Vitamin D concentrations among people aged 65 years and over living in private households and institutions in England: population survey. Age Ageing 34, 485-491.

41. Rennie KL, Wells JCK, McCaffrey TA, et al. (2006) The effect of physical activity on body fatness in children and adolescents. Proc Nutr Soc 65, 393-402.

42. Cole TJ, Fewtrell MS \& Prentice A (2008) The fallacy of using percentage body fat as a measure of adiposity. Am J Clin Nutr 87, 1959. 